\title{
Lithosphere Mapping in Eastern Australia
}

Gaul, O. ${ }^{1}$, O'Reilly, S.Y. ${ }^{1}$, and Griffin, W.L. ${ }^{1,2}$

1. GEMOC National Key, School of Earth Sciences, Macquarie University, NSW 2109, Australia.

2. CSIRO Exploration and Mining, P.O. Box 136, North Ryde, NSW 2113, Australia.

The Australian continent can be broadly divided into two distinct tectonic domains. The western part of the continent consists of a number of cratonic blocks of Archaean and Proterozoic age. The eastern part is made up of a series of terranes which have been accreted to the continent during Phanerozoic time. The boundary between these two domains, the Tasman Line, has been defined by the easternmost outcropping of Precambrian rocks but given the disparate origins of the domains it separates it is likely to reflect an important boundary within the lithospheric mantle as well.

This study aims to understand the differences between these two domains in terms of lithospheric mantle structure, thermal state and chemical composition using data from mantle-derived heavy mineral concentrates. To this end a lithospheric transect has been constructed using data from a series of localities across the Tasman Line in southeastern Australia (Fig. 1).

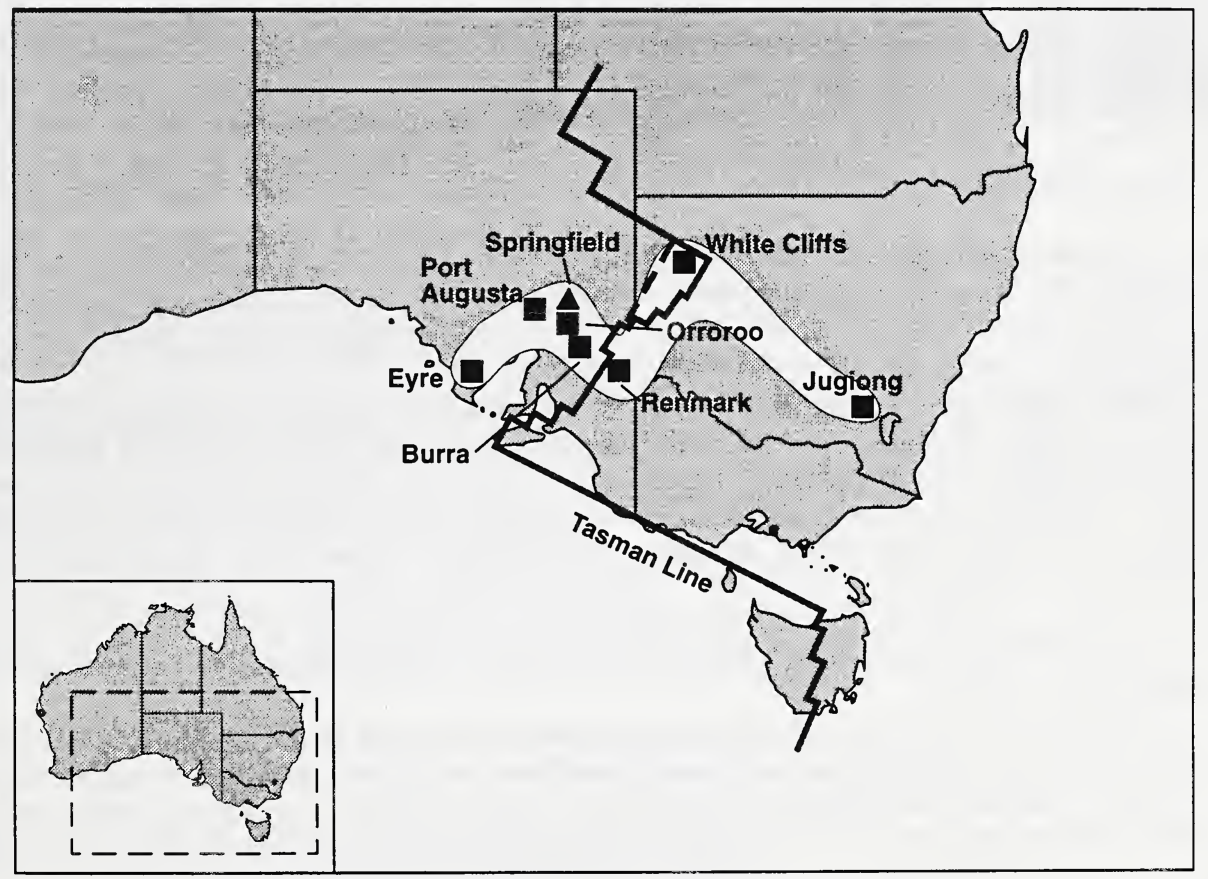

Figure 1. Map showing location of the lithospheric transect across southeastern Australia.

At each locality along this transect a lithospheric section has been produced by determining the geotherm and lithospheric thickness. A lithospheric geotherm can be estimated using the Ni thermometer and Cr barometer of Ryan et al. (1996), which are single mineral methods for use with mantle-derived garnet grains. This information can be used to place each garnet grain in a depth context, which then allows interpretation of changes in lithosphere chemistry with depth. Lithospheric thickness can be estimated for each section through the Y content of garnet grains, on the assumption that Y-depleted garnets are found only within the lithosphere and that asthenospheric garnets have high $\mathrm{Y}$ contents due interaction with melts. Using this reasoning the base of the 
lithosphere can be defined as the temperature above which Y-depleted garnets are no longer found. The temperature can then be referred to the section's geotherm in order to obtain a lithospheric thickness. Results from these lithospheric sections show an increase in lithospheric thickness from east to west, from $100 \mathrm{~km}$ at Jugiong to $160 \mathrm{~km}$ in South Australia (Fig. 2). This increase in lithospheric thickness is accompanied by a decrease in geotherm from one lying above a conductive model equivalent to a surface heat flow of $50 \mathrm{mWm}^{-2}$ at Jugiong, to a more typically cratonic geotherm near the $40 \mathrm{mWm}^{-2}$ conductive model in South Australia.

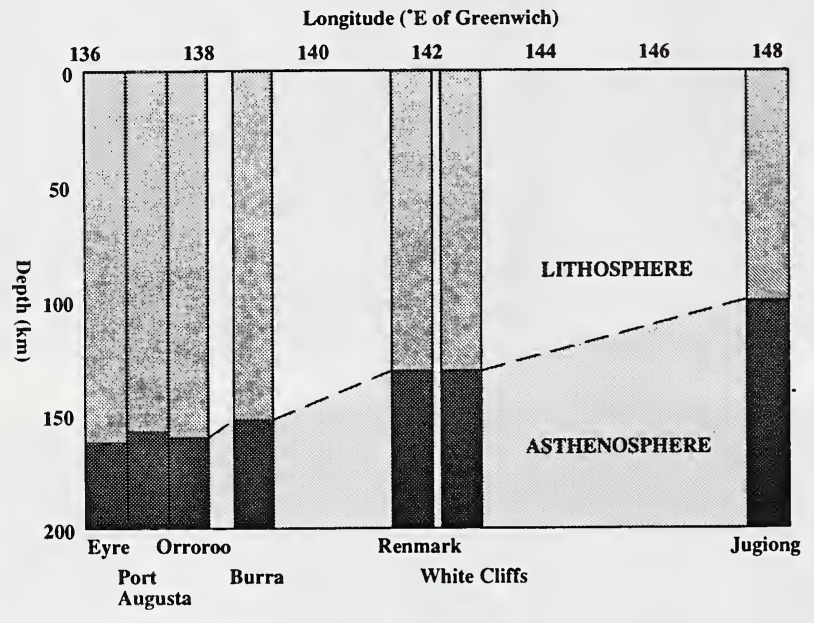

Figure 2. Estimated lithospheric thicknesses for sections on the southern Australian transect
Garnet grains can be classified according to their likely source rock on the basis of their chemistry. In this transect this has been done using the $\mathrm{Ca}$ and $\mathrm{Cr}$ contents of garnets to discriminate between wehrlitic (high $\mathrm{Ca}$ ), lherzolitic (moderate $\mathrm{Ca}$ ) and harzburgitic (low $\mathrm{Ca}$ ) garnets. This method has enabled the use of a template to estimate rock type from garnet chemistry.

The southern Australian localities are characterised by predominantly lherzolitic sections with minor amounts of wehrlitic and Ca-harzburgitic material. The main change across the transect is in the abundance of these minor rock types. In the eastern part of the transect a small proportion of high calcium wehrlitic garnets is seen, whereas in the westerly sections the proportion of this material is much less and a small amount of calcic harzburgitic material is evident.

A more detailed method of looking at variations in lithosphere chemistry through garnet composition is by the construction of "chemical sections". These sections can display facets of garnet chemistry contoured with depth, to study variations in individual elements with depth within sections and across the transect. Chemical sections constructed for this transect show significant variations in minor and trace element characteristics of garnet throughout the transect. Some of the main features observed are:

- maximum $\mathrm{Cr}_{2} \mathrm{O}_{3}$ content of garnet increases from $3 \%$ in Phanerozoic areas to $>10 \%$ in the Proterozoic sections

- mean $\mathrm{TiO}_{2}$ content does not vary systematically across the transect but increases with depth in all sections. This reflects the increasing influence of melt-related metasomatism with depth - mean Y/Ga ratios are extremely high in the Jugiong section and decrease rapidly to the west. This indicates an increase in the degree of depletion in this direction (Griffin et al., 1998)

While garnet can reflect important variations in lithosphere chemistry, it is a minor phase in most lherzolites. Olivine, on the other hand, is the most abundant mantle mineral. The Fe/ $\mathrm{Mg}$ ratio of olivine is an important characteristic of lithospheric composition as it is one of the main determinants of the density of lherzolite due to the high modal proportion of olivine in these rocks. The $\mathrm{Mg}$ content of olivine is also a useful indicator of the degree to which the lithosphere has been depleted through the extraction of basaltic melts. An inversion of O'Neill and Wood's (1979) garnet-olivine Fe-Mg exchange geothermometer, using the equilibrium temperature calculated by the $\mathrm{Ni}$ thermometer in conjunction with the measured garnet composition, has been developed to calculate the Fe-Mg composition of olivine coexisting with each garnet grain. 
The algorithm for implementing this inversion has been tested on garnets from xenoliths where the composition of olivine was known. Xenoliths from both Archaean (Kaapvaal Craton) and Phanerozoic (eastern China) mantle were used in this test to ensure applicability to a variety of tectonic areas. The tests indicate that the inversion can reproduce olivine Fo contents with an error of \pm 0.5 .
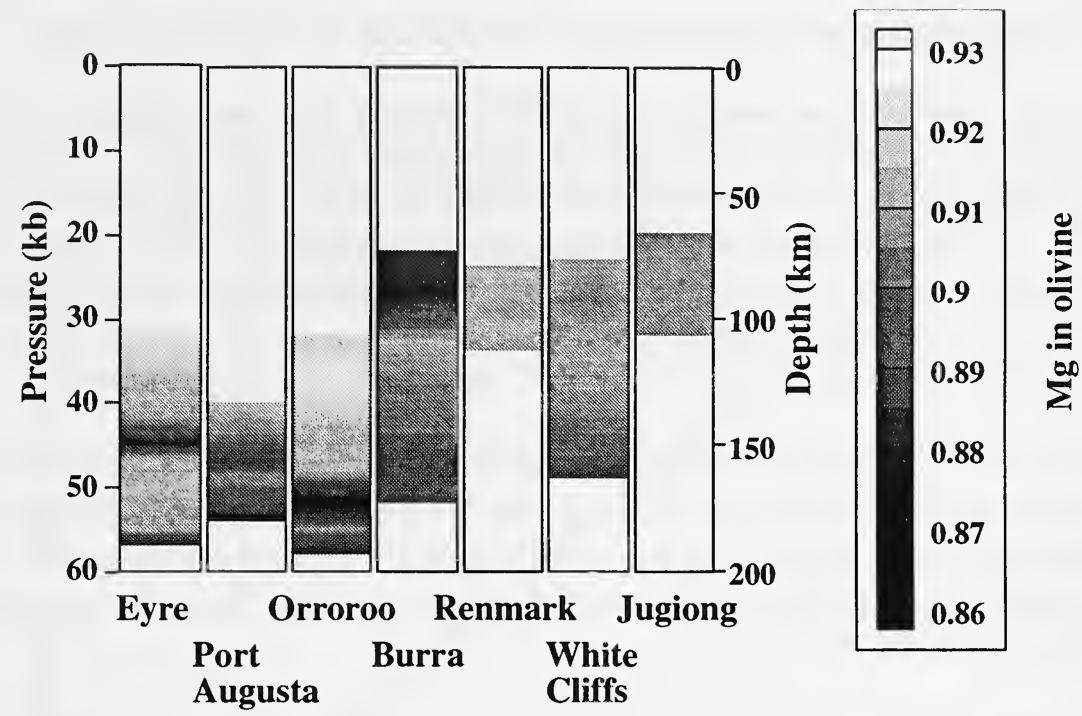

Figure 3. Variation in $\mathrm{Mg}$ content of olivine across the southern Australian transect.

The results of applying this inversion to the southern Australian transect show a core of high $\mathrm{Mg \#}$ olivine in the shallow portions of the most westerly sections (Fig. 3). Olivine in these volumes have Fo contents of 92-93. The easternmost sections have Fo contents of 90-91. The general trend is, therefore, to higher $\mathrm{Mg \#}$ in olivine towards the craton, reflecting a greater degree of depletion beneath the Proterozoic craton. There also is an overall trend to lower values with increasing depth within each section, probably due to the increasing metasomatic effects of melts with depth.

\section{References}

Griffin, W.L., O'Reilly, S.Y., Ryan, C.G., Gaul, O., \& Ionov, D.A., 1992, Secular variation in the composition of subcontinental lithospheric mantle: geophysical and geodynamic implications, in Braun, J., Dooley, J.C., Goleby, B.R., van der Hilst, R.D., \& Klootwijk, C. T., eds., Structure and Evolution of the Australian Continent: AGU Geodynamics Series, 26, 1998, p. 1-26.

O'Neill, H.StC. and Wood, B.J., 1979, An experimental study of Fe-Mg partitioning between garnet and olivine and its calibration as a geothermometer: Contributions to Mineralogy and Petrology, 70, p. 59-70.

Ryan, C.G., \& Griffin, W.L., 1996, Garnet geotherms: Pressure-temperature data from Cr-pyrope garnet xenocrysts in volcanic rocks: Journal of Geophysical Research, 101, p. 5611-5625. 